\title{
Governança em saúde global no contexto das doenças infecciosas emergentes
}

\author{
Global health governance in the context of emerging \\ infectious diseases
}

\author{
Márcia Grisotti*
}

\begin{abstract}
Resumo: Saúde global, enquanto uma categoria política de regulação sanitária internacional, não é nova. Novos são os dispositivos e as configurações políticas transnacionais para administrar as consequências à saúde humana e animal derivadas das interconexões sociopolíticas e ambientais globais. Este artigo analisa como o reposicionamento do papel da Organização Mundial da Saúde - diante dos impactos provocados pelo conceito de doenças infecciosas emergentes (ciência) e pela entrada de novos atores e alianças no núcleo de sua coordenação estratégica (poder), que culminou com a revisão das International Health Regulations (normas) - colocou novos desafios ao regime de segurança em saúde global, diante das ameaças que se difundem além das fronteiras dos estados-nações. Segurança em saúde global implica uma ruptura em relação aos dispositivos tradicionais, ao acentuar o papel de agências e atores transnacionais, porém o sistema de vigilância (registro e notificação de doenças) é dependente dos interesses específicos das esferas nacionais (e locais).
\end{abstract}

Palavras-chave: Saúde global. Doenças infecciosas emergentes. Globalização. Organização Mundial da Saúde.

\begin{abstract}
Global health, as a political category of international health regulation, is not new. New are the devices and transnational policy settings to manage the consequences to human and animal health derived from global sociopolitical and environmental interconnections. This article examines how the repositioning of the role of the World Health Organization - due to the impacts caused by the concept of emerging infectious diseases (science) and the entry of new actors and alliances at the core of its strategic coordination (power), which culminated in the revision of the International Health Regulations (norms) - brought new challenges to the security system of global health in the face of threats that spread beyond the borders of nation-states. Global health security implies a break with the traditional devices by enhancing the role of agencies and transnational actors, but the surveillance system (recording and reporting of diseases) is dependent on the specific interests of national (and local) spheres.
\end{abstract}

Keywords: Global health. Emerging infectious diseases. Globalization. World Health Organization.

\footnotetext{
*Doutora em Sociologia pela Universidade de São Paulo (USP, São Paulo, Brasil), professora do PPG em Sociologia Política da Universidade Federal de Santa Catarina (Ufsc, Florianópolis, SC, Brasil) <grisotti@fastlane.com.br>.
}

Civitas, Porto Alegre, v. 16, n. 3, p. 377-398, jul.-set. 2016 


\section{Introdução}

As políticas e regulações em saúde internacional foram impactadas pelos processos de globalização que aceleraram a interconectividade econômica, tecnológica, industrial e cultural de forma que desterritorializaram o comportamento humano e o meio no qual humanos e micróbios interagem (Fidler, 2004). Na década de 1990, reapareceu o interesse sobre o tema da saúde internacional, ao mesmo tempo em que emergiram vários novos termos como saúde global, diplomacia em saúde, segurança em saúde global, governança global em saúde, tornando-os de uso rotineiro tanto nos debates acadêmicos Fassin (2012) lembra-nos que saúde global se tornou uma disciplina emergente na academia - quanto nas agendas políticas governamentais e de entidades filantrópicas e privadas de muitos países. Porém, o significado desse conceito permanece não devidamente esclarecido.

Por que aumentou o interesse em saúde internacional? Por que esse conceito está sendo substituído por saúde global ou por suas outras variantes terminológicas? No contexto específico das doenças infecciosas emergentes, as ambiguidades e a falta de clareza conceitual também estão presentes: Quando e como podemos falar em doenças velhas, novas e emergentes (ou re-emergentes)?

Os termos saúde global e doenças infecciosas emergentes são constituídos pelo aparato sociotécnico, configurado pela produção do conhecimento científico (que fala sobre humanos e não humanos) e abrange uma complexa rede de atores sociais: cientistas (de diferentes campos acadêmicos), médicos, governos, gestores em vigilância epidemiológica e sanitária, agentes do comércio mundial, meios de comunicação, indivíduos e organizações sociais, assim como, pelas circunstâncias históricas e sociopolíticas, muitas vezes permeadas por conjunturas de incertezas, que produzem normas e regulações (nacionais e internacionais). Neste artigo, procura-se mostrar que a saúde global, enquanto uma questão de política e regulação internacional, não é nova. Novos são os dispositivos e as configurações políticas transnacionais para administrar as consequências à saúde humana e animal derivadas das interconexões sociopolíticas e ambientais globais. No discurso político, o termo globalização da saúde pública expressa a natureza transnacional (e globalizada) das ameaças à saúde pública, pois como os micro-organismos causadores de doenças infecciosas emergentes desconhecem as fronteiras geopolíticas dos estados-nações e os interesses dos estados soberanos, toda a humanidade está vulnerável às ameaças dessas doenças. 
$\mathrm{O}$ aumento das doenças infecciosas emergentes, ou melhor, o aumento do conhecimento sobre elas, e da relação de interdependência entre a saúde humana e animal, através do avanço científico e tecnológico, propiciaram uma nova configuração normativa. Propiciaram ainda uma alteração das respostas políticas de governos e atores sociais não-governamentais sobre como reagir frente aos problemas de ação coletiva que envolvem a governança das doenças infecciosas emergentes no âmbito transnacional (mas que é dependente das esferas locais e nacionais, como veremos mais adiante).

Como apontado por Latour e Woolgar (1979) e antes dele por Kuhn (1970), a ciência e a tecnologia são processos sociais e históricos; e o significado ou justificação de seus argumentos estão vinculados a um conjunto de interesses e posições configuradas em redes sociais.

Com base nessa perspectiva, este artigo pretende analisar os conceitos de saúde global e doenças infecciosas emergentes e seus impactos na reordenação das International Health Regulations (traduzida no Brasil como Regulamento Sanitário Internacional) e no papel da Organização Mundial da Saúde (OMS), no intuito de contribuir no debate contemporâneo sobre os desafios transnacionais do regime de segurança em saúde global, que vão além da capacidade de governança de estados-nações, os quais requerem regimes multilaterais. Sugerimos, com base na análise da literatura, que o reposicionamento do papel da OMS - diante dos desafios provocadas pelo conceito de doenças infecciosas emergentes (ciência), da entrada de novos atores e alianças no núcleo de sua coordenação estratégica (poder), que culminou com a revisão das International Health Regulations (normas) - é fundamental para a compreensão do processo de governança em saúde global, para além das discussões semânticas. Ressaltamos que, neste artigo, como o próprio título sugere, enfocaremos a governança da segurança em saúde global no contexto das doenças infecciosas emergentes. Isso deve ser dito, porque tanto o conceito de saúde global quanto o de doenças emergentes englobam outros tipos de doenças (e, portanto, outros tipos de configurações), além das infecciosas.

$\mathrm{O}$ artigo está dividido em três partes. Com base nas perspectivas de alguns autores, a primeira parte discute o termo saúde global, procurando identificar as posições que o percebem como um novo problema (ou solução) ou como um novo modo de problematizar antigas questões, isto é, novas maneiras de descrever e interpretar a saúde internacional e a saúde pública. É importante ressaltar que, embora comentando injustiças, ao me ater em alguns autores em detrimento de outros, creio que as escolhas realizadas tendem a permitir um bom rendimento analítico sobre o tema central e as questões colocadas neste 
artigo. Na segunda e na terceira parte, recuperamos dois argumentos centrais para a análise das questões colocadas para justificar o termo saúde global: 1) a entrada de novos atores sociais no processo de governança em saúde global e seu impacto no reposicionamento político da OMS e 2) o impacto das doenças infecciosas emergentes no sistema de registro e vigilância global das doenças.

\section{Saúde global: novo conceito ou novos interesses?}

Ações e regulamentações internacionais que envolvem o controle das doenças, que vão além das jurisdições locais e nacionais, não são novas. Respostas coletivas às ameaças à saúde global marcaram, por exemplo, a formação da Organização Mundial de Saúde e outros tipos de cooperações em saúde internacional ao longo do século 21 (Mcinnes e Lee, 2012). A frase "doenças sem fronteiras" (Garrett, 1996; King, 2004) e a ideia de que eventos relacionados às doenças infecciosas que acontecem em uma parte do mundo têm efeitos na saúde em outros países é, há muito tempo, familiar aos historiadores e aos cientistas que trabalham na área da medicina tropical. Avila-Pires (2000) ilustra as contingências históricas do período colonial na produção de conhecimento e controle de doenças: as grandes potências europeias perderam as suas colônias e, com elas, foi-se o interesse pelo estudo das vastas endemias que tanto preocupavam os centros de ensino e pesquisa de medicina tropical. Castro Santos (1985, 2004), Faria e Costa (2010) e Palmer (2015), entre outros autores, analisaram profundamente a cooperação científica internacional promovida pela Fundação Rockfeller na América Latina e Caribe e as relações estabelecidas por ela com os agentes globais e locais de saúde pública.

As consequências adversas e os riscos à saúde derivados do processo de globalização também não são novos. Um dos exemplos do impacto mais devastador da globalização foi a difusão de epidemias mortais que acompanharam os processos de expansão e colonização europeia, e dizimaram várias populações nativas nas Américas e na Oceania. E em relação às medidas de controle, a prática da quarentena ${ }^{1}$ nos estados europeus, no século 14 , que influenciou a moderna saúde pública (Fidler, 1996), fazia parte da rotina sani-

\footnotetext{
${ }^{1}$ O sistema de quarentena foi bem descrito em Rosen (1994, p. 62-63): "Em 1374, Bernabo Visconti, Duque de Milão, promulgou um decreto para prevenir a introdução e a difusão da peste, no qual ordenou a remoção de todos os pacientes da cidade para um campo, onde morreriam ou se recuperariam. Quem tivesse atendido um paciente de peste deveria ser isolado, por quatorze dias, antes de reassumir suas relações sociais com outras pessoas. O mesmo período de observação valia para viajantes ou mercadores infectados ou simplesmente suspeitos de ter a doença. [...] Mais tarde, estendeu-se esse período para quarenta dias [...]. A seguir, em 1383, Marselha construiu suas primeiras estações de quarentena. Assim, depois de rígida inspeção das embarcações, todos os passageiros e cargas de navios com certeza ou suspeita da presença da infecção ficavam detidos por quarenta dias, expostos ao ar e à luz solar".
} 
tária de vários estados, muito antes do advento da teoria microbiana (possível somente no século 20 após as descobertas de Pasteur e Koch) e das explicações científicas sobre a interdependência entre o mundo humano e não-humano.

Em 1851, a França realizou primeira conferência sanitária internacional, com onze estados europeus. De 1851 até o final do século 19, outras dez conferências foram realizadas e oito convenções sanitárias foram negociadas para evitar a disseminação de cólera, peste e febre amarela nas fronteiras geopolíticas dos estados-nações europeus. Já nas Américas, a convenção sanitária interamericana de 1905 impôs a obrigação de notificação de casos de cólera, peste e febre amarela nos países onde ocorressem e, em 1924, foram adicionadas algumas outras doenças de notificação obrigatória, relacionadas à sua possibilidade de disseminação através do comércio internacional (Aginam, 2002).

De acordo com Aginam (2002), o compartilhamento de dados epidemiológicos com a correspondente obrigação dos estados em notificar os surtos em seus territórios fazia parte do escopo dos regimes sanitários e dos mandatos das instituições de saúde multilaterais emergentes: "Surveillance was an important part of the mandate of the Pan-American Sanitary Bureau, Office International d'Higyene Publique, Health Organisation of the League of Nations, and the Office International des Epizooties established in 1924" (Aginam, 2002, p. 947).

Para Brown, Cueto e Fee (2006), os termos internacional, intergovernamental e global não são mutuamente excludentes, assim como saúde global não é uma invenção inteiramente dos anos recentes. De acordo com esses autores, o termo global era usado bem antes dos anos 1990, como no programa de erradicação global da malária, por exemplo, conduzida pela OMS em meados dos anos 1950. Então, o que justifica a mudança dos termos saúde internacional para saúde global?

Artigos publicados, na última década em várias revistas científicas tentam esclarecer a natureza dessa mudança conceitual. Koplan et al. (2009), ao tentarem mostrar a especificidade do conceito de saúde global, acabaram reforçando velhas ideias já trabalhadas pelas declarações e regulamentos internacionais sanitários. De acordo com eles:

global health is an area for study, research, and practice that places a priority on improving health and achieving equity in health for all people worldwide. Global health emphasizes transnational health issues, determinants, and solutions; involves many disciplines within and beyond the health sciences and promotes interdisciplinary collaboration; and is a synthesis of population-based prevention with individual-level clinical care (Koplan et al., 2009, p. 1995). 
A definição proposta por esses autores, portanto, não esclarece a natureza do conceito se atentarmos que no mesmo artigo os autores, ao relatarem os quatro fatores que estabelecem a disciplina saúde pública, acabam aproximando as definições dos dois termos: "(1) decision making based on data and evidence (vital statistics, surveillance and outbreak investigations, laboratory science); (2) a focus on populations rather than individuals; (3) a goal of social justice and equity; and (4) an emphasis on prevention rather than curative care" (Koplan et al., 2009, p. 1993).

Bozorgmehr (2010) considera que Koplan e seus colegas não forneceram pistas para responder à questão crucial para a conceitualização de saúde global: "What is the global in the global health?" ou "o que é o global na saúde global? (tradução da autora).

Fried et al. (2010) consideram que saúde global e saúde pública são indistinguíveis. Brown, Cueto e Fee (2006) questionam se essa mudança de terminologia é um modismo, algo trivial ou diferencial, e resgatam o trabalho de Bunyavanich e Walkup (2001), com entrevistas a 29 líderes de saúde internacional, nas quais metade deles considerou não haver necessidade de uma nova terminologia e a outra metade pensava haver profundas diferenças entre saúde internacional e global, embora fossem incapazes de definir essa mudança.

Para além da discussão puramente semântica do termo saúde global, é no âmbito das atuais configurações do processo de globalização que encontraremos pistas e, possivelmente, ampliaremos o terreno analítico para entender o significado do 'global' na saúde global. Sassen (2010) nos lembra que as formações globais existem há séculos e que vários sociólogos, entre eles Wallerstein (1974), fizeram contribuições importantes para o estudo dessas formações. Esta autora, contudo, chama atenção que, devido às novas configurações das formações globais, a geografia econômica e política, mais do que outras ciências sociais, tem contribuído para o estudo do global, especialmente por causa de sua postura crítica quanto à escala. De acordo com ela, a hierarquia escalar tradicional centrada no estado-nação está sendo desestabilizada pelo impacto das novas dinâmicas (nas esferas do nacional, subnacional e global) e tecnologias, fazendo com que as entidades subnacionais escapem "das hierarquias organizadas em torno do Estado nacional e seu papel como ator supostamente exclusivo em relações internacionais. O foco aqui é nas redes que conectam cidades através de fronteiras e podem cada vez mais superar os Estados nacionais" (Sassen, 2010, p. 16). Global, de acordo com essa autora, "é parcialmente constituído pela desnacionalização de certos componentes daquilo que foi construído como territórios nacionais e domínios nacionais" (Sassen, 2010, p. 17). 
Fidler (1996), ao focar esse debate nos aspectos ligados à saúde, lança mão da polarização entre dois conceitos: globalização versus internacionalização. Esse autor aponta três aspectos dessa polarização: 1) internacionalização envolve a cooperação entre estados soberanos, enquanto que a globalização refere-se a um processo que pode prejudicar ou minar a soberania; 2) a globalização fragiliza as tradicionais distinções entre os assuntos nacionais e estrangeiros; 3 ) as doenças infecciosas emergentes, ao representarem um problema global e necessitarem de estratégias globais, provocam impactos em outras esferas das políticas públicas, tornando mais complexa as tradicionais distinções entre as atividades políticas, sociais e econômicas nacionais e internacionais. Retornaremos mais adiante sobre esse último aspecto, pois estudos têm demonstrado que embora as doenças desconheçam fronteiras geopolíticas, o processo de vigilância, registro e controle das doenças são dependentes dos interesses nacionais (especialmente nas esferas locais) para torná-las públicas.

Como apontamos no início do artigo, os processos de globalização aceleraram a interconectividade econômica, tecnológica, industrial e cultural de uma forma que desterritorializaram o comportamento humano e o meio no qual humanos e micróbios interagem, acarretando mudanças nos dispositivos institucionais de governança e segurança em saúde. Dois fatores, ainda pouco analisados, foram essenciais para essa mudança: 1) a entrada de novos atores sociais no processo de governança em saúde global e seu impacto no reposicionamento político da OMS e 2) o impacto das doenças infecciosas emergentes no sistema de registro e vigilância global das doenças.

\section{Reposicionamento político da OMS e entrada de novos atores sociais}

Brown, Cueto e Fee (2006) discutem o papel da OMS tanto na saúde internacional quanto na saúde global e como ela tem sido um agente na transição de uma terminologia para outra. Esses autores realizaram um detalhado histórico da organização, apontando desde as dificuldades e os conflitos políticos e econômicos encontrados pela OMS, em face de sua crise organizacional, cortes orçamentários dos recursos regulares e poder reduzido, até o seu reposicionamento (através de um conjunto de alianças de poder), no papel de coordenação, planejamento e liderança. ${ }^{2}$

\footnotetext{
${ }^{2}$ No que concerne ao reposicionamento da OMS, Brown, Cueto e Fee (2006, p. 639) relatam a importância do papel da dinamarquesa Brundtland (com uma longa experiência e conhecimento em questões de saúde e meio ambiente), que, ao assumir a presidência da OMS, em 1998, estava determinada a posicionar a OMS como um importante ator no cenário global. "Criou a Comissão sobre Macroeconomia e saúde, presidida pelo economista Jeffrey Sachs e chamou
} 
Com um orçamento limitado para executar as funções tradicionais (relativas às ações de controle das doenças de notificação obrigatória), a estrutura da OMS não conseguiu acompanhar as demandas dos problemas globais em saúde pública, especialmente aqueles relacionados ao monitoramento das doenças infecciosas emergentes. Nesse contexto, a OMS viu seu papel e prestígio, antes dominante no cenário internacional, ser desafiado, quando entraram em cena outros atores poderosos, como os bancos de desenvolvimento regionais e multilaterais liderados pelo Banco mundial, Organização para o desenvolvimento e cooperação econômica (OCDE), Forum econômico mundial, e o boom em recursos filantrópicos para a saúde global, desde 1990, entre eles, a Fundação Bill e Melinda Gates e doadores de fundos privados (Mcinnes e Lee, 2012).

Weir (2012) discute os fatores políticos que estão por trás da troca dos termos que envolvem a função principal da OMS - de controle obrigatório internacional de doenças comunicáveis para a segurança em saúde global. De acordo com a autora, uma aliança Estados Unidos-Canadá, a partir de 1993, chamou a atenção da OMS para as responsabilidades inerentes ao controle das doenças infecciosas emergentes, ou seja, de outras doenças que não constavam na lista de doenças de notificação obrigatória da própria organização. O debate sobre as doenças infecciosas emergentes encontrava-se difundido na literatura desde meados dos anos 1990, e estava ligado às ameaças à saúde global, interesse primordial dos Estados Unidos. ${ }^{3}$

Respondendo a essa demanda, a OMS, em 1995, estabeleceu a divisão de controle e vigilância de doenças emergentes e outras doenças comunicáveis. Em 1996, estabeleceu um plano estratégico de detecção e controle de surtos chamado world on alert, que de acordo com Weir (2012) estava na base da formação do conceito de segurança em saúde global. De acordo com a autora, esse plano tinha como objetivo o controle das doenças comunicáveis através

ex-funcionários do Banco Mundial, da OMC, do Fundo monetário internacional (FMI), do Programa das Nações Unidas para o desenvolvimento (Pnud) e lideranças em saúde pública para avaliar as condições de saúde dos países em desenvolvimento, condição considerada por ela como essencial para o crescimento econômico. Além dessa reorientação política, Brundtland pretendia fortalecer a situação financeira trazendo para dentro da organização outros atores econômicos que incluíam as parcerias público/privadas, fundos globais, doadores privados e agência bilaterais".

${ }^{3}$ Brown, Cueto e Fee (2006), mencionam que nesse período teve início a publicação do jornal Emerging Infectious Disease pelo Center for Disease Control and Prevention (CDC) nos Estados Unidos, seguidos por uma série de relatórios governamentais norteamericanos sobre o tema e inúmeros livros (alguns na lista dos mais vendidos) e revistas repletos de "estórias" sobre exemplos de doenças infecciosas emergentes, incluindo as ameaças de bioterrorismo. 
de uma rede global de monitoramento, trocas de informações eletrônicas, sistemas de prontidão nacionais e internacionais, rápida resposta, controle e vigilância nacional; objetivos esses que entravam em conflito com o sistema político-jurídico anterior de notificação internacional de doenças comunicáveis contidas na lista de doenças de notificação obrigatória.

A necessidade de fontes complementares de monitoramento e vigilância, de um conhecimento mais completo e em real-time pela OMS, levou ao funcionamento, em 1998, da Global public health intelligence network (GPHIN), então localizada no Health Canada (um ministério federal). Desde então, essa rede tem sido a fonte primária de informações não-oficiais sobre surtos (Weir, 2012).

Novas formas de notificação de doenças foram introduzidas através de um sistema de monitoramento global via internet ${ }^{4}$ e de relatos de eventos (ao invés de relatos de casos-diagnósticos). Esse aparato, construído entre 1996 e 2005, operou em um espaço experimental extra-legal, politicamente protegido pela resolução 48.7 da Assembléia mundial em saúde, sendo oficializado a partir da revisão das International Health regulations (traduzida no Brasil como Regulamento Sanitário Internacional), em 2005. Weir (2012) considera que essa revisão permitiu colocar:

global health security within the sphere of juridical right by reconceptualizing what must be reported to WHO, the target of mandatory action, and the powers of WHO. Mandatory report is of the event (a disease or a condition that creates the potential for disease) rather than the case of a known communicable disease, significantly expanding the remit of global public health governance.

Após a aprovação dessa regulamentação, de acordo com Weir (2012), fazia pouco sentido chamar as atividades relacionadas com emergências em saúde pública internacional pelo antigo termo - controle de doenças comunicáveis. Desde então, segundo a autora, o termo segurança em saúde global passou a ser mais utilizado e, enquanto um regime, teria uma estrutura formada por uma constituição jurídico-política, um modo sociotécnico de governança e trocas de informações oficiais e não-oficiais. Para a autora, a nova regulação efetuou

\footnotetext{
${ }^{4}$ Iniciativas como o ProMED-mail - the Program for monitoring emerging diseases, um sistema online de relato e de rápida disseminação de informações sobre surtos de doenças infecciosas em humanos, animais e plantas e exposições agudas a toxinas que afetam a saúde humana, é um dos exemplos de novas formas de governança em saúde global e que ampliaram o escopo restrito das atividades desempenhadas pela OMS, que se limitava ao registro de casos de algumas doenças de notificação obrigatória.
} 
uma mudança jurídico-política que constituiu a OMS como um poder global supra-soberano que pode (ao limite) declarar emergências em saúde pública internacionais na ausência de consentimento soberano.

A partir de 2005, sob o novo Regulamento, 194 estados membros são obrigados a reportar Pheics - Potential public health emergencies of international concern (emergências potenciais de saúde pública de interesse internacional) - à OMS dentro de 72 horas desde a identificação de um evento. Uma Pheics é definida como um evento extraordinário que "constitute a public health risk to other States through international spread of disease" $\mathrm{e}$ "potentially require a coordinated international response" (Kohl et al., 2012, p. 1048). Em adição a qualquer doença com risco de dispersão internacional, certas doenças listadas devem sempre ser avaliadas e quatro doenças (influenza humana causada por um novo subtipo de virus, poliomielite, sarampo e Sars) devem ser imediatamente reportadas à OMS. Os quatro critérios que guiam as avaliações são: 1) Is the public health effect of the event serious? 2) is the event unusual or unexpected? 3) is there a major risk for international spread? 4 ) is there a major risk for travel or trade restriction? If 2 of the 4 criteria are met, the event must be reported to WHO (Kohl, et al., 2012, p. 1048).

A revisão do regulamento sanitário internacional permitiu, portanto, a expansão do escopo das doenças passíveis de serem reportadas (e notificadas), fortaleceu e alargou os requerimentos de registros e incorporou explicitamente as considerações relativas aos direitos humanos. Essas medidas visavam a redução dos riscos de disseminação global das doenças infecciosas emergentes.

\section{$O$ impacto das doenças infecciosas emergentes no sistema de registro e vigilância global das doenças}

As expectativas de controle e erradicação de doenças infecciosas e parasitárias - com o advento da teoria da origem microbiana das doenças infecciosas, seguidas pela produção de soros e vacinas no fim do século 20, bem como, pela descoberta de sulfas e antibióticos no século 20 - não se confirmaram. A emergência da Aids e de um número de doenças zoonóticas no final do século 20, fragilizaram o conceito de transição epidemiológica, no qual supunha-se (ou especulava-se) que as doenças infecciosas e parasitárias dariam lugar às condições crônicas e degenerativas como as principais causas de mortalidade e morbidade humana (Grisotti, 2010).

O crescimento populacional e a pressão sobre os recursos naturais, o aumento da pobreza, o aparecimento de resistências aos antibióticos, as migrações forçadas (por questões ambientais, econômicas ou políticas), a fome, o processo de urbanização e a migração de populações rurais para as 
cidades e a sua instalação em zonas sem saneamento básico, são razões que podem ser identificadas como tendo contribuído para a emergência de doenças infecciosas (Grisotti, 2010).

Além disso, os microorganismos são versáteis e possuem um amplo alcance de adaptações às condições ambientais adversas. Avanços no entendimento sobre os seus processos biológicos, na produção de novas gerações de medicamentos e vacinas e no melhoramento de barreiras sanitárias para impedir sua dispersão têm se mostrado mais lentos do que a capacidade de mutação, recombinação e dispersão demonstrada pelos microorganismos (Ochman, Lawrence e Groisman, 2000).

Estamos assistindo a uma evolução dos biomas relacionada com as modificações no meio ambiente introduzidas pelos seres humanos. A expansão contínua das terras agrícolas em áreas selvagens e o contato com o gado e animais domésticos, o boom mundial da produção e tráfego de bovinos vêm sendo responsáveis pela emergência de doenças zoonóticas emergentes em várias regiões do mundo.

Entretanto, a falta de conexão entre a ciência médica e a veterinária, bem como, da vigilância epidemiológica ser repartida entre a área da saúde e a área da agricultura/pecuária, de forma independente e desarticulada, tende a dificultar as ações de prevenção e controle dessas doenças (Grisotti, 2003; Meditsch, 2006; Santos, 2013).

Um dos temas prioritários da Organização Pan-americana de Saúde (Opas é a articulação entre a saúde animal e humana, a reavaliação dos sistemas de informação e vigilância epidemiológica e as estratégias de comunicação social (OMS/Opas, 2003). Na mesma direção, o relatório da Organização das Nações Unidas para alimentação e agricultura (FAO, 2013), alerta que cerca de $70 \%$ das novas doenças que infectaram os seres humanos nas últimas décadas tiveram origem animal, tornando-se cada vez mais comum que doenças mudem de espécies e se espalhem na população, em meio ao crescimento das cadeias de agricultura e de abastecimento alimentar. O comércio e a circulação rápida de pessoas, animais, plantas, microorganismos e mercadorias explicam a intensificação da disseminação de agentes patogênicos e sua emergência em escala global.

A globalização enquanto conceito e enquanto experiência tem gerado respostas e situações ambivalentes. Ao mesmo tempo em que o processo de globalização é colocado como facilitador e dispersor de agentes patogênicos, ele também tem possibilitado o desenvolvimento de processos de diplomacia e regulações internacionais, bem como, permitido a produção e difusão de conhecimentos sobre doenças e vetores, aumentando, assim, as chances de 
uma consciência de interdependência, requerida para a governança global em saúde. Paralelamente aos esforços governamentais, emergiram, nos últimos anos, iniciativas como, por exemplo, a One health initiative, composta por indivíduos da sociedade civil e organizações científicas e profissionais, que incentivam estratégias mundiais para expandir as colaborações e comunicações interdisciplinares em todos os aspectos de atenção à saúde entre humanos, animais e meio ambiente.

Se, por um lado, a globalização implica a revisão das diferenças entre doenças de países desenvolvidos e doenças de países subdesenvolvidos, já que dadas as atuais características da globalização, todos os países vivem situações de risco (Grisotti, 2010), por outro lado, alguns países (especialmente os mais pobres e com baixo poder de influência nas decisões internacionais) são mais vulneráveis às doenças. Este contexto ambivalente nos remete às questões: Por que algumas doenças são eleitas como foco de atenção em detrimento de outras? Por que algumas doenças são consideradas problema de saúde pública enquanto outras passam pela periferia do debate acadêmico e das políticas de atenção à saúde? Como o poder está configurado e como são feitas as escolhas políticas em relação aos processos de tomada de decisão que envolvem riscos à saúde?

Mesmo reconhecendo que os fatores socioeconômicos têm contribuído tanto para a emergência e disseminação de doenças quanto para o seu possível controle (Inhorn e Brown, 2004), a redução das desigualdades sociais não tem sido alvo de propostas concretas nas políticas de saúde global, assim como, os impactos socioeconômicos decorrentes do processo de diagnóstico e de divulgação da "existência" das doenças emergentes em países vulneráveis do ponto de vista econômico e humanitário, não são avaliados. A recorrência na literatura aos termos doenças negligenciadas (Hotez et al., 2007) e desigualdades sociais em saúde (Farmer, 1996) são ilustrativas dessa ambiguidade, bem como reforça a necessidade de análise interdependente das dimensões estruturais e culturais no estudo da história social das doenças. As explicações das doenças emergentes apenas pelos fatores culturais e comportamentais têm gerado interpretações equivocadas e, muitas vezes, situações de estigma e preconceito.

Um bom exemplo que ilustra as ambivalências da governança em saúde global encontra-se nas tentativas globais de controle da epidemia do Ebola, quando comparados com a negligência em relação às milhões de mortes devido às consequências da diarreia no mesmo continente. No caso do Ebola, o foco na atribuição dos riscos de contágio do ponto de vista biomédico e a imediata crítica (e supressão) à forma como as comunidades locais organizavam os 
funerais, escondia a história de um longo processo que iniciou em 1976, quando o vírus foi identificado e o médico descobridor já, naquela época, alertava para as poucas medidas que seriam necessárias para se evitar uma epidemia no Zaire (Piot, 2012). Somente quando os casos de ebola romperam as fronteiras de alguns países africanos, atingindo os EUA e Europa, ela passou a ser encarada como um problema de saúde pública (global) e medidas práticas para a sua contenção foram adotadas.

Em contraposição, as mortes devido às consequências das diarreias em vários países africanos (cujas causas, agentes patogênicos e doenças a elas relacionadas, em geral, não são investigadas) permanece silenciosa: mais de 4 milhões de casos de diarreia ocorrem todo ano com uma média de 2,2 milhões de mortes, sendo 37\% dos casos na África Subsaariana, com uma média de 7,7\% de todas as mortes registradas anualmente (Koné et al., 2014). No entanto, ela não faz parte das escolhas políticas sobre as doenças a serem tratadas como um problema de saúde pública global. Além disso, é importante notar que durante a epidemia de ebola, as agências de saúde das Nações Unidas forneceram conselhos e suporte às nações impactadas, mas não forneceram staff suficiente para atenção aos pacientes, função essa desempenhada muito mais por organizações não-governamentais, tais como Médicos sem fronteiras.

Diante desse quadro apresentado, doenças consideradas como negligenciadas (para as quais há pouco interesse em pesquisa científica e recursos destinados a sua vigilância e controle) e/ou endêmicas em muitos países, convivem com outras doenças consideradas de alto impacto para a saúde pública global, como por exemplo, a Aids, febres hemorrágicas (ebola, lassa, nipah, hanta, marburg), Sars, algumas gripes causadas pelos agentes influenza (H1N1 e H5N1), encefalopatia espongiforme bovina (BSE) entre tantas outras epidemias e pandemias chamadas de doenças infecciosas emergentes.

Em artigo publicado na coletânea Advances in medical sociology (Grisotti e Avila Pires, 2010), identificamos o uso inadequado da expressão doenças infecciosas emergentes, e chamamos a atenção para as diferenças entre a abordagem pragmática do conceito pelo Centro de controle e prevenção de doenças dos Estados Unidos (CDC) e a abordagem históricoepistemológica realizada por Grmek (1993, 1995). Na perspectiva do CDC, as doenças infecciosas emergentes são aquelas que apareceram recentemente em uma população ou aquelas que já existiam, mas por algum motivo, estão se espalhando mais rapidamente, em termos de incidência ou distribuição geográfica (Lederberg et al., 1992). Tal disseminação pode ser devido a uma introdução recente de um novo agente etiológico ou a uma mutação de um 
agente existente, seguido pela sua rápida disseminação entre a população (Morse, 1995).

Pelo fato de nem sempre podermos saber se uma doença é nova ou se é existente, mas não detectável, Grmek (1993) expandiu o conceito de doenças emergentes, apresentando quatro situações nas quais as doenças poderiam ser assim denominadas:

1. ela existia antes de ser reconhecida pela ciência (o caso da doença de Chagas é exemplar: investigações epidemiológicas revelaram que ela afetava milhões de pessoas antes de ser descoberta pelos cientistas em 1909. Para além do debate epistemológico em torno das perspectivas construtivistas e realistas implícitas nessa situação, destacamos a dimensão mais sociopolítica da questão, formulado por Gire et al. (2012): há um aumento do número das doenças emergentes ou foram os diagnósticos "emergentes" que possibilitaram a identificação de muitas doenças e patógenos que estavam circulando mais largamente do que imaginado pelos cientistas?);

2. ela já existia mas aumentou em seu grau de letalidade em função de mudanças qualitativas e quantitativas em seu ambiente (o caso da legionella, uma bactéria simples mas letal quando concentrada em precários sistemas de refrigeração/calefação);

3. ela foi introduzida em uma região onde não existia anteriormente (o caso das diversas doenças ditas tropicais);

4. ela emerge a partir da passagem de um reservatório não-humano para humano (o caso das inúmeras doenças zoonóticas).

Para Grmek (1993), a única possibilidade de uma doença ser considerada como nova advém da possibilidade de acidentes ocasionados por manipulação de organismos patogênicos em laboratório, bioterrorismo ou manipulações genéticas. Porém, mesmo nessa possibilidade Grmek reconhece a existência de uma certa continuidade com o passado, pois nenhum organismo pode originar-se de geração espontânea.

Como as ações em saúde pública global dependem do conhecimento sobre a incidência e prevalência de doenças (ou em outras palavras, das informações sobre o que circula no ambiente), paralelamente às situações apontadas por Grmek, incluímos, no artigo citado, uma sexta situação que consideramos crucial para determinar a emergência de uma doença: o papel da subnotificação das doenças de notificação obrigatória e a falência no reconhecimento e registro de doenças "incomuns" (Grisotti e Avila Pires, 2010).

Esse aspecto tem sido um dos maiores limitadores do processo de vigilância e controle das doenças, pois essas ações somente são possíveis 
de serem planejadas e executadas com êxito se os dados de registro forem corretos e coletados sistematicamente. Como eles dependem das esferas locais de gestão do sistema de vigilância em saúde, isso afeta consideravelmente as expectativas em torno das atividades em saúde global. Em um mundo de estados-nações soberanos, a saúde continua a ser primariamente uma responsabilidade nacional e apesar dos acordos e regulações internacionais sobre a segurança global em saúde, os dados que alimentam o sistema são produzidos localmente e, nessa esfera, fatores extra-epidemiológicos influenciam o interesse em registrar e notificar doenças. Por exemplo, os casos de raiva bovina, febre aftosa, tuberculose bovina nas fronteiras produtoras de gado no sul da América Latina, ilustram o dilema sobre como lidar com questões de saúde que ultrapassam as fronteiras dos estados-nações. Como realizar o controle quando um dos estados vizinhos é livre das doenças e outros não são? Quem será responsável e como serão realizadas as ações de controle? E no caso de indenizações, de quem é a responsabilidade? Quais as consequências econômicas da notificação de doenças em animais com grande valor no mercado da carne?

As doenças zoonóticas passaram a ocupar um lugar central nas agendas e acordos políticos de muitos países, e as medidas sanitárias passaram a fazer parte das exigências para a efetivação de muitos acordos internacionais, principalmente aqueles interessados na exportação de produtos de origem animal. Por exemplo, no Brasil foi criado, em 2001, o programa nacional para o controle e erradicação da brucelose e tuberculose, para reduzir o impacto negativo dessas zoonoses e promover a competitividade nacional na produção de leite e carne e, em 2002, o Serviço de rastreabilidade da cadeia produtiva de bovinos e bubalinos (Sisbov), que tem como finalidade acompanhar a cadeia produtiva bovina, especificando a forma de manejo, modo de alimentação e procedimentos sanitários aos quais os animais devem ser submetidos. Esse processo é operacionalizado por uma base de dados, alimentada por informações oriundas da identificação e certificação do animal (Brasil, 2007).

Nesse contexto, aos atores sociais anteriormente envolvidos no sistema (produtores rurais, frigoríficos, governo e seus programas e regulações específicos) uma nova rede de atores foi incorporada ao sistema como, por exemplo, os fornecedores de insumos, consultorias privadas e estatais, os profissionais da fiscalização (nacionais e internacionais) e as certificadoras, que avaliam o sistema de rastreabilidade do gado e garantem o status de propriedade livre de certas doenças animais e as fábricas de elementos de identificação (brincos, por exemplo). 
Esses programas apresentam vários problemas que foram identificados por Santos (2013), entre eles, o fato de funcionar por adesão voluntária do produtor de carne. Ou seja, apesar de ter sido criado para controlar toda a cadeia produtiva de bovinos, na prática, o sistema é aplicado apenas em algumas propriedades, geralmente de grandes proprietários interessados no mercado exportador de carne bovina. Nessas propriedades, o rastreamento das condições sanitárias e a saúde dos animais segue, aparentemente, todas as normas e protocolos internacionais. Mas, como vimos anteriormente, os microorganismos, os vetores e os reservatórios de doenças desconhecem fronteiras geopolíticas e isso explica a permanência da doença em muitas propriedades que não aderiram ao sistema, bem como o reaparecimento, por exemplo, da brucelose (assim como da tuberculose de origem bovina), em algumas propriedades nacionais controladas, por estarem situadas nas fronteiras entre os países e/ou as propriedades que não seguem os programas de sanidade e rastreabilidade bovina.

Além dos problemas relacionados à vigilância em saúde humana e animal nas fronteiras entre estados-nações, existem outros problemas relacionados com as fronteiras entre os espaços rural e urbano. Embora a ocorrência da brucelose e da tuberculose de origem bovina, entre outras doenças de origem animal, seja mais frequente nas áreas rurais do país, o impacto para a saúde humana ocorre, também, nas cidades, por serem os centros de distribuição e consumo de produtos de origem rural (o leite e o queijo, por exemplo, nos casos de brucelose e tuberculose bovina). Grande parte dos consumidores urbanos de produtos oriundos de "feiras de produtos coloniais" geralmente desconhecem que esses produtos são produzidos sem algum tipo de controle. Do ponto de vista dos pequenos produtores de carne e leite, as variações do mercado os levam a criarem alternativas, tais como vender alimentos de origem animal em feiras coloniais nas cidades. Outra prática de comércio é a chamada de "venda à janela" na qual comercializam pequenas quantidades de produtos ao se deslocarem para a cidade para estudar, fazer compras ou ir ao médico. Essas formas de comércio escapam, muitas vezes, de qualquer estratégia de controle dos órgãos oficiais (Santos, 2013).

Além disso, a falta de articulação e diálogo entre os setores da vigilância da agricultura, da saúde e do meio ambiente e a fraca vigilância de muitos animais silvestres (hospedeiros de diversos microorganismos patogênicos), que entram na cadeia produtiva do gado, tornam o controle do rebanho ainda mais fragilizado.

Essa falta de articulação institucional é resultado de posições e interesses políticos. Mas também importante é a falta de articulação entre os campos das 
clínicas médica e veterinária e o campo da epidemiologia. Por exemplo, no Brasil, não é realizado o diagnóstico diferencial do Micobacterium responsável pela tuberculose. Para um bacteriologista, há diferentes patógenos envolvidos, mas para o clínico essa distinção é irrelevante, pois o tratamento será o mesmo (com antibióticos). Por outro lado, para as finalidades da saúde pública (e global) a identificação e diferenciação das espécies de patógenos é fundamental para o processo de notificação (e produção de dados epidemiológicos), para saber o que está circulando no ambiente e para antecipar, com maior precisão, as medidas de controle e vigilância da fonte de transmissão (humana ou animal).

\section{Considerações finais: desafios da governança em saúde global}

Para além da discussão semântica sobre o termo saúde global, vimos, neste artigo, que o reposicionamento da OMS diante dos impactos provocados pelas doenças infecciosas emergentes e pela entrada de novos atores sociais em seu núcleo de poder foram fatores que tornaram possível a emergência dos termos saúde global e regime de segurança em saúde global, por alterarem os dispositivos institucionais tradicionais que regiam a saúde internacional. Nesse contexto, novas regulações internacionais foram produzidas com o objetivo de governar as ameaças que extrapolam as fronteiras dos Estados-nações.

No entanto, tal como evidenciado por Sassen (2010), o reescalonamento que atravessa o tamanho e os limites institucionais do território produzidos pela formação dos Estados nacionais não significa que as antigas hierarquias desapareceram. O processo de governança em saúde global e a vigilância dos riscos sanitários e epidemiológicos de doenças infecciosas emergentes continuam a depender: da forma como são realizadas as notificações de casos ou eventos de doenças, através dos sistemas de vigilância em saúde nas esferas locais (municipais) dos países onde os eventos (ou surtos) de doenças acontecem; da forma como são diagnosticadas as doenças nas áreas da saúde humana e animal e como são constituídos e interpretados esses dados; de quais são os interesses (políticos, econômicos e culturais) em jogo para tornar "real" a existência de uma doença, bem como considerá-la como problema de saúde pública; dos mecanismos de coordenação e do compartilhamento de informações, essenciais para assegurar respostas às ameaças que se difundem além das fronteiras dos estados-nações.

As novas configurações produzidas pelo Regulamento Sanitário Internacional de 2005, no plano teórico, preveem uma rápida troca de informações entre a OMS e estados membros que viabilize uma resposta global mais coordenada e transparente. No plano ideológico, isso requer uma 
consciência da interdependência entre os setores responsáveis pelas diferentes ações necessárias para enfrentar as ameaças das doenças infecciosas emergentes e uma diminuição da tensão entre os imperativos da soberania nacional e as ações coletivas internacionais para administrar essa interdependência. Contudo, permanece a questão: como e quem fará as escolhas sobre as doenças que receberão mais atenção (e recursos)? No plano pragmático, isso vai requerer: 1) uma melhoria na estrutura e funcionamento dos sistemas de vigilância em saúde e sua conexão mais ativa e direta com as unidades locais de saúde, nas quais os dados são produzidos; 2) formação de pessoal (acadêmico e técnico) qualificado e capacitado de forma contínua para a investigação interdisciplinar; 3) um estreitamento das lacunas existentes entre a produção de conhecimento acadêmico e os processos políticos de tomada de decisões em vigilância à saúde. Sobre esse aspecto, estudos sobre o caso da pandemia de H1N1 ilustram o impasse entre agir (baseado em evidências científicas) em casos de possíveis epidemias, e ser criticado se elas não ocorrerem como previstas, ou falhar ao agir (ou não-agir) e ser criticado se elas ocorrerem (Davis et al., 2014).

As novas formas de organizações sociais estão desafiando a primazia dos estados-nações na arena global. Por exemplo, redes da sociedade civil, sistemasperitos, fundações filantrópicas, corporações multinacionais e jornalistas, todos exercem poder em processos de governança global em seus países de origem, mas nenhum meio efetivo existe para regular as responsabilidades de atores não-governamentais operando na arena global sobre os efeitos de suas ações. Diante desse contexto, Frenk e Moon (2013) advertem sobre a falta de mecanismos claros e instituições efetivas para estabelecer o diálogo e o acordo com muitos atores não-governamentais que influenciam a saúde global.

Outro desafio é avaliar quem vai administrar as externalidades do processo de prevenção e mitigação dos efeitos negativos à saúde sobre situações ou decisões que podem ter efeitos sobre os outros indivíduos e sociedades ou, ainda, sobre as situações que rompem com as fronteiras dos Estadosnações. A falta de mecanismos para o agenciamento das responsabilidades dificulta a gestão de externalidades. Por exemplo, um governo pode atrasar a divulgação de um surto de doença por medo de repercussões econômicas. Impasses semelhantes podem ocorrer em países com conjunturas políticas permeadas por situações de conflitos, guerras, governos corruptos ou com extrema pobreza.

No contexto dos grandes desafios e incertezas em relação às novas configurações das formações globais, e mais especificamente o seu impacto 
sobre as questões relacionadas à saúde, a ciência política e a sociologia precisam urgentemente problematizar, através de suas peculiares ferramentas teóricas e metodológicas, essas novas configurações e trajetórias envolvidas nos processos de governança em saúde global.

\section{Referências}

AGINAM, O. International law and communicable diseases. Bulletin of the World Health Organization, v. 80, n. 12, p. 946-951, 2002.

AVILA-PIRES, F. D. Princípios de ecologia médica. Florianópolis: UFSC, 2000.

BOZORGMEHR, K. Rethinking the 'global' in global health: a dialetic approach. Globalization and health, v. 6, n. 19, $2010<10.1186 / 1744-8603-6-19>$.

BRASIL. Ministério da agricultura, pecuária e abastecimento. Novo Sisbov Brasil. Cadeia Produtiva da Carne Bovina. Brasília: Mapa, 2007.

BROWN, T. M.; CUETO, M.; FEE, E. A transição de saúde pública "internacional” para "global" e a Organização Mundial da Saúde. História, Ciências, Saúde Manguinhos, v. 13, n. 3, p. 623-647, $2006<10.1590 /$ S0104-59702006000300005>.

BUNYAVANICH, S.; WALKUP, R. B. US public health leaders shift toward a new paradigm of global health. American Journal of Public Health, v. 91, n. 10, p. 15561558, $2001<10.2105 /$ AJPH.91.10.1556>.

CASTRO SANTOS, L. A. de. Estado e saúde pública no Brasil (1889-1930). DadosRevista de Ciências Sociais, v 23, n. 2, p. 237-250, 1985.

CASTRO SANTOS, L. A. de. Poder, ideologias e saúde no Brasil da primeira república: ensaio de sociologia histórica. In: Gilberto Hochman; Diego Armus (orgs.). Cuidar, controlar, curar: ensaios históricos sobre saúde e doença na América Latina e Caribe. Rio de Janeiro: Fiocruz, 2004. p. 249-293.

DAVIS, M.; FLOWERS, P. e STEPHENSON, N. We had to do what we thought was right at the time. Sociology of Health \& Illness, v. 36, n. 3, p. 369-382, 2014 $<10.1111 / 1467-9566.12056>$.

FAO. World Livestock 2013, Changing disease landscapes, Rome, 2013.

FARIA, L.; COSTA, M. C. Cooperação científica internacional: estilos de atuação da Fundação Rockfeller e da Fundação Ford. In: L. A. Castro Santos e L. Faria (orgs.). Saúde \& história. São Paulo: Hucitec, 2010. p. 211-241.

FARMER, P. Social inequalities and emerging infectious diseases. Emerging infectious disease, v. 2, n. 4, p. 259-269, $1996<10.3201 /$ eid0204.960402>.

FASSIN, D. That obscure object of global health. In: M. C. Inhorn; E. A. Wentzell (orgs.). Medical anthropology at the intersections. London: Duke University Press, 2012. p. 95-115.

FIDLER, D. P. Globalization, international law, and emerging infectious diseases. Emerging infectious disease, v. 2, n. 2, p. 77- 84, $1996<10.3201 /$ eid0202.960201>. 
FIDLER, D. P. Sars, Governance and globalization of disease. New York: Palgrave Macmillan, 2004.

FRENK, J.; MOON, S. Global health: Governance challenges in global health. The New England Journal of Medicine, v. 368, n. 10, p. 936-942, $2013<10.1056 /$ NEJMra1109339>.

FRIED, L. P.; BENTLEY, M. E.; BUEKENS, P.; BURKE, D. S.; FRENK, J. J.; KLAG, M.J.; SPENCER, H. Global health is public health. Lancet, v. 375, n. 9714, p. 535-537, $2010<10.1016 /$ S0140-6736(10)60203-6>.

GARRET, L. The return of infectious disease. Foreign Affairs, v. 75, n. 1, p. 66-79, 1996.

GIRE, S. K.; STREMLAU, M.; ANDERSEN, K. G.; SCHAFFNER, S. F.; BJORNSON, Z.; RUBINS, K.; HENSLEY, L.; McCORMICK, J. B. LANDER, E. S.; GARRY, R. F.; HAPPI, C.; SABETI, P. C. Emerging disease or diagnosis? Science, v. 338, n. 6108, p. $750-752,2012<10.1126 /$ science. $1225893>$.

GRISOTTI, M. Saúde e meio ambiente: a construção médica e popular de uma doença infecciosa emergente. São Paulo, 2003. Tese de doutorado, Faculdade de Filosofia, Letras e Ciências Humanas, Universidade de São Paulo.

GRISOTTI, M. Doenças infecciosas emergentes e a emergência das doenças: uma revisão conceitual e novas questões. Ciência e Saúde Coletiva, v. 15, supl. 1, p. 1095$1104,2010<10.1590 /$ S1413-81232010000700017>.

GRISOTTI, M.; AVILA-PIRES, F. D. The concept of emerging infectious disease revisited. In: Ananya Mukherjea (ed.). Understanding emerging epidemics: social and political approaches. Advances in medical sociology. v. 11. Londres: Emerald, 2010. p. $61-75<10.1108 / \mathrm{S} 1057-6290(2010) 0000011008>$.

GRMEK, M. D. Le concept de maladie émergente. History and Philosophy of the Life Sciences, v. 15, p. 282-296, 1993.

GRMEK, M. D. Declin et émergence des maladies. História, Ciências, Saúde Manguinhos, v. 2, n. 2, p. 9-32, $1995<10.1590 /$ S0104-59701995000300002>.

HOTEZ, P. J.; MOLYNEUX, D. H.; FENWICK, A.; JACOB KUMARESAN, M. B.; SACHS, S. E.; SACHS, J. D.; SAVIOLI, L. Currect concepts: control of neglected tropical diseases. The New England Journal of Medicine, v. 357, n. 10, p. 1018-1027, $2007<10.1056 /$ NEJMra064142>.

INHORN M. C.; BROWN P. J. Introduction. In: M. C. Inhorn; P. Brown (orgs.). The anthropology of infectious disease: International health perspectives. New York: Routledge, 2004. p. 3-29.

KING, N., B. The scale politics of emerging diseases. Osiris, The University Chicago Press, v. 19, p. 62-76, $2004<$ http://www.jstor.org/stable/3655232>.

KOHL, K. S.; ARTHUR, R. R.; O'CONNOR, R.; FERNANDEZ, J. Assessment of public health events through international health regulations, United States, 20072011. Emerging infectious Disease, v. 18, n. 7, p. 1047-1053, 2012. 
KONÉ, B.; DOUMBIA, M.; SY, I.; DONGO, K.; AGBO-HOUENOU, Y.; HOUENOU, P. V.; FAYOMI, B.; BONFOH, B.; TANNER, M.; CISSÉ, G. Étude des diarrhées en milieu périurbain à Abidjan par l'approche écosanté. Vertigo - la revue électronique en sciences de l'environnement [Online], hors-série 19, août $2014<10.4000 /$ vertigo.14976>.

KOPLAN, J. P.; BOND, T. C.; MERSON, M. H.; REDDY, K. S.; RODRIGUEZ, M. H.; SEWANKAMBO, N. K.; WASSERHEIT, J. N. Towards a common definition of global health. Lancet, v. 373, n. 9679, p. 1993-1995, $2009<10.1016 /$ S01406736(09)60332-9>.

KUHN, T. The structure of scientific revolutions. 2. ed. Chicago: University of Chicago Press, 1970.

LATOUR, B.; WOOLGAR, S. Laboratory life: the social construction of scientific facts. Los Angeles: Sage, 1979.

LEDERBERG, J.; SHOPE, R. E.; OAKS, S. Emerging infectious: microbial threats to health in the United States. Washington: National Academy Press, 1992.

MCINNES C.; LEE, K. Global health and international relations. Cambridge: Polity Press, 2012.

MEDITSCH, R. G. M. O Médico veterinário, as zoonoses e a Saúde Pública: um estudo com profissionais e clientes de clínicas de pequenos animais em Florianópolis, SC, Brasil. Florianópolis, 2006. Dissertação de mestrado, Programa de pós-graduação em Saúde Pública, Universidade Federal de Santa Catarina.

MORSE, S. S. Factors in the emergence of infectious diseases. Emerging Infectious Diseases, v. 1, n. 1, p. 7-15, $1995<10.3201 /$ eid0101.950102>.

OCHMAN, H. LAWRENCE, J. G.; GROISMAN, E. A. Lateral gene transfer and the nature of bacterial innovation. Nature, v. 405, p. 299-304, $2000<10.1038 / 35012500>$.

OPAS/OMS. Relatório do Programa de saúde pública veterinária sobre o cumprimento das orientações estratégicas e programáticas da repartição sanitária panamericana, 1999-2002. Washington, DC, 2003.

PALMER, S. Gênese da saúde global: a Fundação Rockfeller no Caribe e na América Latina. Rio de Janeiro: Fiocruz, 2015.

PIOT, P. No time to lose: a life in pursuit of deadly viruses. New York-London: W.W. Norton \& Company, 2012.

ROSEN, G. Uma história da saúde pública. 2. ed. São Paulo: Hucitec, Editora da Unesp, Abrasco, 1994.

SASSEN, S. Sociologia da globalização. Porto Alegre: Artmed, 2010.

SANTOS, C. A. O Brasil e o mercado internacional de carne bovina no contexto de doenças infecciosas emergentes: uma análise sociopolítica dos programas de sanidade animal e de normativas de segurança. Florianópolis, 2013. Tese de doutorado, Programa de Pós-graduação em Sociologia Política, Universidade Federal de Santa Catarina. 
WALLERSTEIN, I. Capitalist agriculture and the origins of the European worldeconomy in the sixteenth century. The modern world-system I. New York: Academic Press, 1974.

WEIR, L. A genealogy of global health security. International Political Sociology, v. 6, n. 3, p. 322-325, $2012<10.1111 /$ j.1749-5687.2012.00166_4.x>.

Autor correspondente:

Marcia Grisotti

Rua Haroldo Soares Glavan, 3820, casa 5. Cacupé

88050-005 Florianópolis, SC, Brasil

Recebido em: 22 mar. 2016

Aprovado em: $1^{\circ}$ set. 2016 